\title{
Identification of Antifungal Compounds from the Root Bark of Cordia anisophylla J.S. Mill.
}

\author{
Quentin Favre-Godal, ${ }^{a}$ Sébastien Pinto, ${ }^{a}$ Stephane Dorsaz, ${ }^{b}$ Adriano Rutz, ${ }^{a}$ \\ Laurence Marcourt, ${ }^{a}$ Mahabir Gupta, ${ }^{c}$ Dominique Sanglard, ${ }^{b}$ Emerson F. Queiroz ${ }^{\circledR * a}$ \\ and Jean-Luc Wolfender ${ }^{a}$ \\ ${ }^{a}$ School of Pharmaceutical Sciences, EPGL, Université de Genève, CMU, Rue Michel-Servet 1, \\ Geneve 1211, Switzerland \\ ${ }^{b}$ Institute of Microbiology, University of Lausanne and University Hospital Center, Lausanne, \\ Switzerland \\ ${ }^{c}$ Center of Pharmacognostic Research on Panamanian Flora (CIFLORPAN), College of Pharmacy, \\ University of Panama, P.O. Box 0824-00172, Panama City, Panama
}

\begin{abstract}
The dichloromethane extract of the root bark of the Panamanian plant Cordia anisophylla J.S. Mill. (Boraginaceae) presented antifungal activity against a susceptible strain of Candida albicans in a bioautography primary screening. The susceptible strain was used to detect minor active compounds that would not have been detected using a classical approach. In order to identify the antimicrobial compounds, the active extract was fractionated by semi-preparative high-performance liquid chromatography and the fractions were submitted to the antifungal bioassay. This procedure enabled a precise localization of the antifungal compounds directly in the chromatogram of the crude extract and allowed for an efficient, targeted isolation. Four compounds were isolated, one of which is a new natural product. The structures were elucidated using spectroscopic methods. Their antifungal properties were evaluated by determination of the minimum inhibitory quantity and concentration by bioautography and dilution assay against a wild type strain of C. albicans.
\end{abstract}

Keywords: Cordia anisophylla, Candida albicans, susceptible strain, antifungal, HPLC-microfractionation

\section{Introduction}

The genus Cordia, consisting of around 250 species, is the largest group in the Boraginaceae family. It is widely distributed, and is especially present in Central and South America. ${ }^{1}$ The genus has been widely studied, leading to the identification of a series of antifungal metabolites, such as the cordiaquinones $\mathrm{B}, \mathrm{E}, \mathrm{G}$ and $\mathrm{H}$ from Cordia linnaei and cordiaquinones $\mathrm{A}, \mathrm{B}, \mathrm{J}$ and $\mathrm{K}$ from the roots of C. curassavica. $^{2,3}$ The phytochemical investigation of Cordia alliodora led to the identification of a phenylpropanoid derivative characterized as 1-(3'-methoxypropanoyl)-2,4,5-trimethoxybenzene and a prenylated hydroquinone, 2-(2Z)-(3-hydroxy3,7-dimethylocta-2,6-dienyl)-1,4-benzenediol, both active against Cladosporium cucumerinum. ${ }^{4}$ Recently, two neolignans isolated from the fruit of Cordia exaltata showed weak antimicrobial activity against a variety of pathogens including Candida albicans. ${ }^{5}$

Cordia anisophylla J.S. Mill. is a small tree that grows from the center of Panama to the border of Columbia. In our continuous search for antifungal compounds of natural origin, ${ }^{6-9}$ the dichloromethane (DCM) extract of the root bark of $C$. anisophylla demonstrated significant antifungal activity in a primary bioautography screen against $C$. albicans, one of the most opportunistic fungi that infects humans. ${ }^{10}$ C. albicans can colonize human skin and mucosal surfaces, causing a wide spectrum of diseases ranging from benign mucosal infections such as oral thrush to fatal disseminated candidiasis. ${ }^{10}$ The present study reports the isolation and structure elucidation of the antifungal compounds from the DCM extract of the root bark of C. anisophylla.

*e-mail: emerson.ferreira@unige.ch 


\section{Results and Discussion}

The dichloromethane extract of the roots of C. anisophylla presented antifungal activity in a thin layer chromatography (TLC) bioautographic assay against $C$. albicans with a minimum amount of $20 \mu \mathrm{g}$ deposited. In order to localize the compounds responsible for the antifungal activity, $40 \mathrm{mg}$ of the crude extract was submitted to a semi-preparative high performance liquid chromatography (HPLC)-UV fractionation yielding 49 fractions. ${ }^{8}$ A direct transfer of the analytical HPLC-UV conditions to a semi-preparative HPLC using the same stationary phase provided a rational and efficient fractionation, ${ }^{11,12}$ as most HPLC fractions corresponded to single peaks (Figure 1b). Because the microfractions were obtained from a high-resolution chromatography separation, bioautography was performed directly on the microfractions that were previously transferred to the TLC plate without any further elution step. ${ }^{8}$ This approach allowed for good correlation of the extract's antifungal activity with one peak at $28 \mathrm{~min}$ and a series of LC peaks eluting between 35 and $38 \mathrm{~min}$, as compared to only one active zone detected in the primary screen (Figure 1c).

In order to identify compounds present in the active extract, the crude extract was initially analyzed by ultra-performance liquid chromatography (UPLC)time of flight-high resolution mass spectrometry
(TOF-HRMS) for dereplication purposes. HRMS data obtained were compared to compounds reported in the Boraginaceae family and the Cordia genus (see Tables S1 and S2, Supplementary Information (SI) section). The UPLC-TOF-HRMS analysis at positive mode, showed a molecular ion at $\mathrm{m} / \mathrm{z} 349.1448[\mathrm{M}+\mathrm{H}]^{+}$ (retention time $\left(\mathrm{t}_{\mathrm{R}}\right)=2.43 \mathrm{~min}$; calculated for $\mathrm{C}_{22} \mathrm{H}_{20} \mathrm{O}_{4}$, $348.1375 ; \Delta \mathrm{ppm}=3.9)$ attributed to the known quinone ehretiquinone (3), previously isolated from Ehretia longiflora, Boraginaceae. ${ }^{13}$ Using the same approach the molecular ion at $m / z, 393.3381[\mathrm{M}+\mathrm{H}]^{+}\left(\mathrm{t}_{\mathrm{R}}=4.66 \mathrm{~min}\right.$; calculated for $\mathrm{C}_{25} \mathrm{H}_{44} \mathrm{O}_{3}, 392.3308 ; \Delta \mathrm{ppm}=4.5$ ) was attributed to the known alkyl phenol derivative (1-(4-hydroxyphenyl)-3,5-nonadecanediol(3S,5R), previously isolated from Heliotropium sinuatum, Boraginaceae. ${ }^{14}$ The HRMS analysis also highlights the presence of two other compounds (quinone derivative, $\mathrm{t}_{\mathrm{R}}=2.48 \mathrm{~min}, \mathrm{~m} / z 351.1592[\mathrm{M}+\mathrm{H}]^{+}$and fatty acid derivative, $\mathrm{t}_{\mathrm{R}}=3.82 \mathrm{~min}, \mathrm{~m} / z 277.2176[\mathrm{M}+\mathrm{H}]^{+}$) already reported from the Boraginaceae family, however, these compounds could not be precisely identified since many hits could be linked to the data obtained (see Tables S1 and S2, SI section). HRMS data of the remaining compounds were not sufficient for any early structure assignments. The presence of different unknown metabolites and the lack of phytochemical studies in this species justify a phytochemical investigation.

(a)

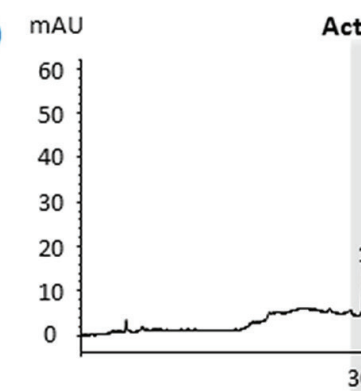

(b)

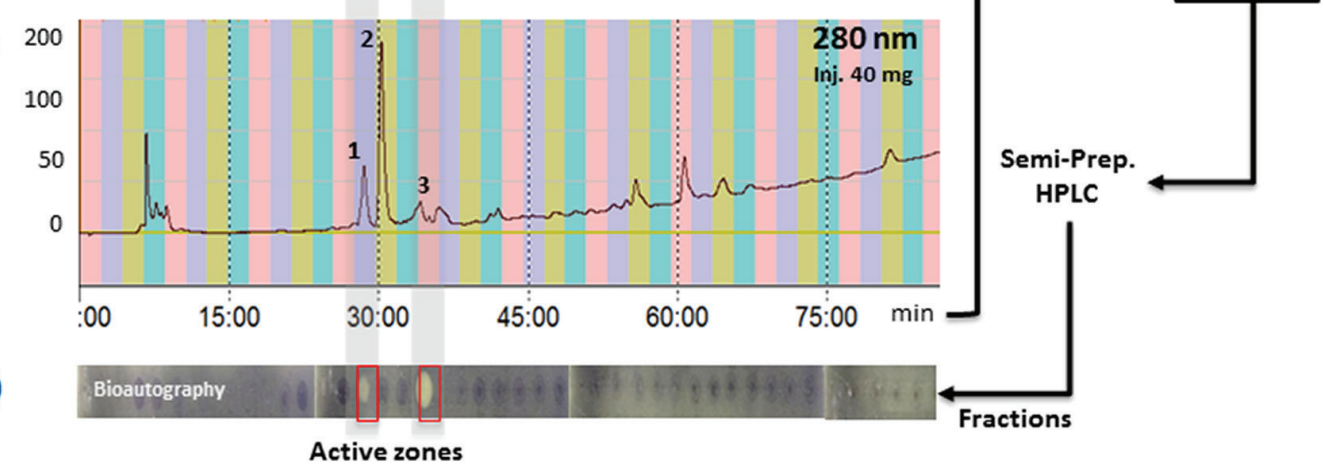

Figure 1. (a) HPLC-photo-diode array (PDA) at $280 \mathrm{~nm}$ : analysis of the roots DCM extract of C. anisophylla; (b) semi preparative HPLC-UV at $280 \mathrm{~nm}$; (c) antifungal bioautography after microfractionation. 
In order to fully characterize the antifungal agents detected by the above-described procedures, the active compounds were isolated by flash chromatography (FC) and semi-preparative HPLC. A direct transfer of the analytical HPLC conditions to FC using the same stationary phase material provided a satisfactory fractionation of $2.5 \mathrm{~g}$ of the crude DCM extract. ${ }^{15}$ The final semi-preparative HPLC resulted in the isolation of four pure compounds 1-4 that were fully characterized by nuclear magnetic resonance (NMR) and HRMS analyses. The isolated secondary metabolites were identified as 6-hydroxy2,2-dimethyl-3-chromen (1), ${ }^{16}$ ehretiquinone $(\mathbf{3})^{13}$ and gentisaldehyde (4). ${ }^{17}$ Beside these known compounds, the separation afforded one new compound (2), described below (Figure 2).<smiles>CC1(C)C=Cc2cc(O)ccc2O1</smiles>

1

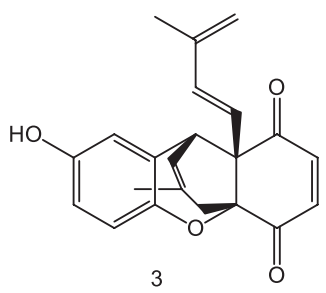

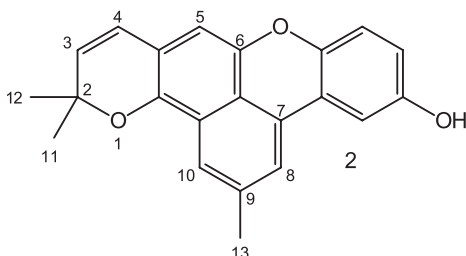

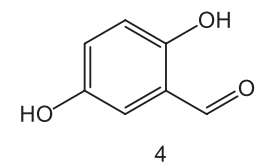

Figure 2. Structures of the isolated compounds from the roots DCM extract of C. anisophylla.

Compound $\mathbf{2}$ was isolated as an amorphous solid. The electrospray ionization (ESI)-HRMS spectrum showed a molecular ion at $\mathrm{m} / \mathrm{z} 330.1251[\mathrm{M}]^{+}$(calculated for $\mathrm{C}_{22} \mathrm{H}_{18} \mathrm{O}_{3}, 330.1256 ; \Delta \mathrm{ppm}=1.5$ ). A cross search of this molecular formula using the dictionary of natural products (DNP) database ${ }^{18}$ for plants of the genus Cordia did not give any hits. The ${ }^{1} \mathrm{H}$, correlation spectroscopy (COSY), heteronuclear single quantum correlation (HSQC) and heteronuclear multiple bond correlation (HMBC) spectra showed the presence of four cycles. The first cycle (A) was a disubstituted 2,2-dimethyl- $2 \mathrm{H}$-pyran as indicated by two ortho-aromatic protons at $\delta_{\mathrm{H}} 5.74$ and 6.39 for $\mathrm{H}-3$ and $\mathrm{H}-4$, respectively $(\mathrm{J} 9.7 \mathrm{~Hz})$ and the two equivalent methyls at $\delta_{\mathrm{H}} 1.47\left(\mathrm{CH}_{3}-11,12\right)$ carried by a tertiary oxygenated carbon $\left(\delta_{\mathrm{C}} 77.0, \mathrm{C}-2\right)$. The second cycle (B) was probably pentasubstituted, as shown by the singlet aromatic proton at $\delta_{\mathrm{H}} 6.53(\mathrm{H}-5)$. Cycle $\mathrm{C}$ was a 3,4,5-trisubstituted toluene, as depicted by the methyl at $\delta_{\mathrm{H}} 2.47\left(\mathrm{CH}_{3}-13\right)$ and two meta coupled protons at $\delta_{\mathrm{H}} 7.36$ and $7.55(\mathrm{H}-8$ and $\mathrm{H}-10$, respectively, $J 1.5 \mathrm{~Hz}$ ). The $\mathrm{HMBC}$ correlations between $\mathrm{CH}_{3}-13$ and $\mathrm{C}-8, \mathrm{C}-9$ and $\mathrm{C}-10\left(\delta_{\mathrm{C}} 117.2,137.6,119.8\right.$, respectively) allowed the positioning of the methyl and aromatic protons. Cycle D was a 1,3,6-trisubstituted aromatic as shown by its proton pattern at $\delta_{\mathrm{H}} 6.74(\mathrm{dd}$, $1 \mathrm{H}, J$ 8.7, $2.8 \mathrm{~Hz}, \mathrm{H}-4^{\prime}$ ), 6.88 (d, 1H, J 8.7 Hz, H-5') and 7.25 (d, $\left.1 \mathrm{H}, J 2.8 \mathrm{~Hz}, \mathrm{H}-2^{\prime}\right)$. The HMBC correlations from $\mathrm{H}-5$ to $\mathrm{C}-4\left(\delta_{\mathrm{C}} 123.4\right)$ and $\mathrm{C}-1 \mathrm{a}\left(\delta_{\mathrm{C}} 141.7\right)$ and from $\mathrm{H}-4$ to C-5 $\left(\delta_{\mathrm{C}} 104.9\right)$ and $\mathrm{C}-1 \mathrm{a}$ allowed to link cycle $\mathrm{A}$ to $\mathrm{B}$, the correlations from $\mathrm{H}-5$ to $\mathrm{C}-1 \mathrm{a}$ and $\mathrm{C}-6 \mathrm{a}\left(\delta_{\mathrm{C}} 120.9\right)$, from H-10 to C-1a and C-6a and from H-8 to C-6a linked cycle $\mathrm{B}$ to $\mathrm{C}$ (Figure 3). Cycle $\mathrm{C}$ was connected to cycle $\mathrm{D}$ via $\mathrm{C}-7$ and $\mathrm{C}-1$ ' as showed by the correlations from $\mathrm{H}-8$ to C-1' $\left(\delta_{\mathrm{C}} 121.1\right)$ and C-7 $\left(\delta_{\mathrm{C}} 127.9\right)$, from H-5' to C-1' and from $\mathrm{H}-2$ ' to C-7. The chemical shift values of C-6, C-3' and C-6' $\left(\delta_{\mathrm{C}} 145.9,154.1\right.$ and 146.8 , respectively) indicated that they are substituted with oxygens. Finally, to fit with the $\mathrm{C}_{22} \mathrm{H}_{18} \mathrm{O}_{3}$ molecular formula, a fifth ring (E) had to be present, linking C-6 to C-6' via an oxygen. The nuclear Overhauser effect (NOE) correlations between $\mathrm{H}-4$ and $\mathrm{H}-5$ and between $\mathrm{H}-8$ and $\mathrm{H}-2$ ' are in good agreement with the structure proposed for compound $\mathbf{2}$. The new secondary metabolite (2) was named anisophenol.

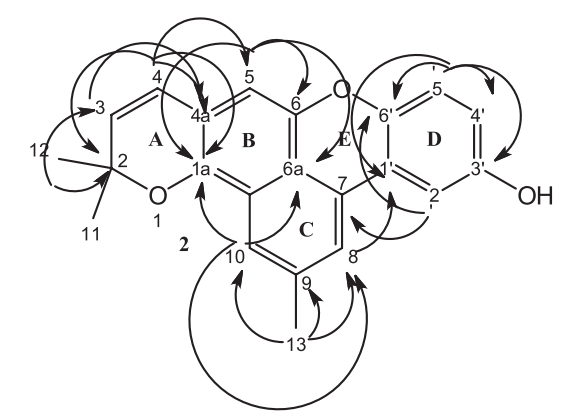

Figure 3. HMBC correlations of compound 2.

The minimal inhibitory quantity (MIQ), that defines the minimum quantity required to produce an inhibition zone in the TLC bioassay, of the isolated compounds and the crude extract against the wild type (CAF2-1) and susceptible strains (DSY2621) of C. albicans are presented in Table 1. The susceptible strain was used to have a more sensitive detection of antifungal agents according to our protocol. ${ }^{8}$ Compounds $\mathbf{1}, \mathbf{3}$ and $\mathbf{4}$ were more active against the susceptible strain, with the lowest MIQ observed for compound $\mathbf{3}(\leq 5 \mu \mathrm{g})$. This compound also presented the lowest MIQ against the wild type strain of $C$. albicans with a value of $25 \mu \mathrm{g}$. The minimum inhibitory concentrations (MICs) of the compounds were investigated according to the EUCAST method..$^{19}$ Compounds 1-4 were inactive in broth dilution assays at the concentration tested. The isolated compounds did not present any activity against mature biofilm. ${ }^{20}$ 
Table 1. Bioautography, broth dilution assay and biofilm evaluation of the extract, isolated and reference compounds

\begin{tabular}{|c|c|c|c|c|}
\hline \multirow[b]{2}{*}{ Compound } & \multicolumn{2}{|c|}{ Bioautography assay MIQ / $\mu \mathrm{g}$} & \multirow{2}{*}{$\begin{array}{c}\text { Dilution assay } \mathrm{MIC} /\left(\mu \mathrm{gL}^{-1}\right) \\
\begin{array}{l}\text { C. albicans } \\
(\mathrm{CAF} 2-1)^{\mathrm{b}}\end{array}\end{array}$} & \multirow{2}{*}{$\begin{array}{c}\text { Mature biofilm / }\left(\mu \mathrm{g} \mathrm{mL}^{-1}\right) \\
\text { C. albicans } \\
(\mathrm{CAF} 2-1)^{\mathrm{b}}\end{array}$} \\
\hline & $\begin{array}{l}\text { C. albicans } \\
(\text { DSY2621) }\end{array}$ & $\begin{array}{l}\text { C. albicans } \\
(\mathrm{CAF} 2-1)^{\mathrm{a}}\end{array}$ & & \\
\hline Crude extract & 20 & d & $\mathrm{d}$ & $\mathrm{d}$ \\
\hline 1 & 30 & d & d & d \\
\hline 2 & ND & ND & d & d \\
\hline 3 & $\leq 5$ & 25 & d & d \\
\hline 4 & $\leq 15$ & d & d & d \\
\hline Miconazole $^{c}$ & 0.0006 & 0.005 & 0.0156 & ND \\
\hline
\end{tabular}

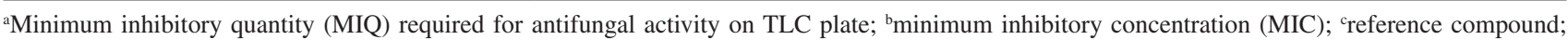
dinactive: MIQ $>50 \mu \mathrm{g}$; MIC $>32 \mu \mathrm{g} \mathrm{mL}^{-1}$; biofilm $>50 \mu \mathrm{g} \mathrm{mL}^{-1}$. ND: not determined.

\section{Conclusions}

HPLC activity-based metabolite profiling enabled a rapid and efficient identification of the antifungal compounds from the DCM extract of the root bark of Cordia anisophylla. The targeted isolation of selected compounds by gradient transfer from analytical HPLC-photodiode array (PDA) to FC-UV allowed efficient purification for further bioactivity and structural investigation. From a chemotaxonomic viewpoint, the presence of 6-hydroxychromenol (1) and quinone derivatives (3) are in agreement with previous studies ${ }^{21,22}$ on the Cordia genus where similar compounds have been described. Even though the isolated compounds showed antifungal activity against the susceptible strain on the bioautography assay, they did not show antifungal activity in a broth micro-dilution plate against $C$. albicans at the concentration tested.

\section{Experimental}

General

UV spectra were measured on a PerkinElmer Lambda 20 spectrophotometer (Waltham, MA, USA). LC-PDA data were obtained with an Agilent 1100 series system (Santa Clara, CA, USA) consisting of an auto sampler, a high-pressure mixing pump and a PDA. HRESIMS data were obtained on a Micromass-LCT Premier TOF mass spectrometer (Waters, MA, USA) with an electrospray interface. The NMR spectroscopic data were recorded on a $500 \mathrm{MHz}$ Varian Inova spectrometer (Palo Alto, CA, USA). Chemical shifts are reported in parts per million $(\delta)$ using the residual $\mathrm{CD}_{3} \mathrm{OD}$ signal $\left(\delta_{\mathrm{H}} 3.31 ; \delta_{\mathrm{C}} 49.0\right)$ and $\mathrm{CDCl}_{3}$ signal $\left(\delta_{\mathrm{H}} 7.26 ; \delta_{\mathrm{C}} 77.16\right)$ as internal standards for ${ }^{1} \mathrm{H}$ and ${ }^{13} \mathrm{C}$ NMR, respectively, and coupling constants $(J)$ are reported in $\mathrm{Hz}$. Complete assignment was performed using 2D experiments such as COSY, edited-HSQC, HMBC and NOESY. Analytical HPLC was carried out on an HP 1100 system equipped with a photodiode array detector (Agilent Technologies, Santa Clara, CA, USA). The FC was performed with a modular preparative FC-UV system (Puriflash 4100, Interchim, Montluçon, France) equipped with a quaternary pump, a UV detector module, and a fraction collector. Semi-preparative HPLC was carried out with a Spotprep Liquid Chromatography (Armen instrument, Saint-Avé, France).

\section{Collection and identification of the plant material}

The bark from roots of Cordia anisophylla J.S. Mill. (Boraginaceae) was collected in Panama in Coclé, Barrigón, El Copé. A voucher specimen (No. 7094) was deposited at the National Herbarium of Panama, Panama City.

\section{Extraction}

The air-dried plant material (700 g) was pulverized with a Wiley mill, and extracted at room temperature with dichloromethane $(3 \times 1 \mathrm{~L})$ and concentrated under pressure yielding $2.7 \mathrm{~g}(0.3 \%)$.

HPLC-PDA-evaporative light scattering detector (ELSD) analysis

HPLC-PDA-ELSD data were obtained with an Agilent 1100 series system (Santa Clara, CA, USA) consisting of an auto sampler, high-pressure mixing pump and PDA detector connected to an ELSD (Sedex 85, Sedere Omnilab, Altfortville, France). HPLC conditions: X-Bridge C-18 column $(5 \mu \mathrm{m}, 250 \times 4.6 \mathrm{~mm}$ i.d.; Waters, Milford, MA, USA); solvent system: $\mathrm{A}=0.1 \%$ formic acid $-\mathrm{H}_{2} \mathrm{O}$, $\mathrm{B}=0.1 \%$ formic acid-MeOH; gradient mode: 45 to $79 \%$ of 
B from 0 to 30 min, held constant at $79 \%$ of B from 30 to $50 \mathrm{~min}$, from 79 to $100 \%$ of B in $10 \mathrm{~min}$ and held constant at $100 \%$ during $10 \mathrm{~min}$; flow rate: $1 \mathrm{~mL} \mathrm{~min}^{-1}$; injection volume $10 \mu \mathrm{L}$ and sample concentration $10 \mathrm{mg} \mathrm{mL}^{-1}$ in $\mathrm{MeOH}$. The UV traces were recorded at 210 and $254 \mathrm{~nm}$ and UV spectra (PDA) were recorded between 190 and $600 \mathrm{~nm}$ (step $2 \mathrm{~nm})$.

\section{Semi-preparative HPLC-UV fractionation}

$500 \mu \mathrm{L}$ of the dichloromethane extract of $C$. anisophylla (40 mg) was injected in the Armen modular spot prep II (Saint-Avé, France) prep instrument with a Cosmosil silice SL-II $\left(250 \times 10 \mathrm{~mm}\right.$ i.d.; $5 \mu \mathrm{m}$, Nacalai Tesque ${ }^{\circledR}$, Kyoto, Japan). The extract was purified using a flow rate of $4.7 \mathrm{~mL} \mathrm{~min}^{-1}$ with the following mobile phase system: hexane (A) and ethyl acetate (B). The separation was performed using a gradient mode as follow: $3 \% \mathrm{~B}$ from 0 to $1 \mathrm{~min}, 3$ to $37 \% \mathrm{~B}$ from 11 to $52 \mathrm{~min}, 37$ to $70 \% \mathrm{~B}$ from 52 to $87 \mathrm{~min}, 70$ to $100 \% \mathrm{~B}$ from 87 to $92 \mathrm{~min}$. Detection was performed by UV at $280 \mathrm{~nm}$. The fractions were collected in 49 glass tubes and evaporated to dryness using a SpeedVac (HT-4X Genevac $®$, Stone Ridge, NY, USA). The content of each tube was suspended in $40 \mu \mathrm{L}$ of DCM and spotted on the thin layer chromatography plate of silica gel GF 254 coated A1 sheets (Merck, Darmstadt, Germany) for the biological assay. ${ }^{8}$

\section{Isolation}

The dichloromethane $(2.5 \mathrm{~g})$ extract was first fractionated using FC (Puriflash ${ }^{\circledR}$, Armen Instruments ${ }^{\circledR}$, Saint-Avé, France) with a Puriflash® SiHP 80 g column $\left(276 \times 35 \mathrm{~mm} ; 15 \mu \mathrm{m}\right.$, Interchim ${ }^{\circledR}$, Montluçon, France $)$ using a UV detector at $280 \mathrm{~nm}$, flow rate of $10 \mathrm{~mL} \mathrm{~min}^{-1}$ with hexane (A) and ethyl acetate (B) as a mobile phase in a gradient mode as follows: $10 \% \mathrm{~B}$ from $0-8 \mathrm{~min}, 10$ to $35 \%$ B from 8-109 $\mathrm{min}, 35$ to $65 \%$ B from $109-175 \mathrm{~min}$ and finally 65 to $100 \% \mathrm{~B}$ from 175 to $177 \mathrm{~min}$. The separation yielded 96 fractions (F1 to F96). The purification of the fractions was performed by semi-HPLC using a normal phase HPLC on a Cosmosil® column $(250 \times 10 \mathrm{~mm}$ i.d., $5 \mu \mathrm{m}$, Phenomenex, Kyoto, Japan $)$ with a mixture of hexane (A) and ethyl acetate (B) as a mobile phase. The final purification of fraction F19 (50 mg) was performed using a gradient mode as follows: 5 to $100 \%$ of $\mathrm{B}$ in $40 \mathrm{~min}$, injection of $500 \mu \mathrm{L}\left(10 \mathrm{mg} \mathrm{mL}^{-1}\right)$, flow rate $4.7 \mathrm{~mL} \mathrm{~min}^{-1}, \mathrm{UV}$ at $254 \mathrm{~nm}$ yielded $\mathbf{1}(1.5 \mathrm{mg})$. The separation of fractions F24-25 (15 mg) was performed in isocratic mode with $3 \%$ during $20 \mathrm{~min}$, injection of $500 \mu \mathrm{L}\left(15 \mathrm{mg} \mathrm{mL}^{-1}\right)$, flow rate $4.7 \mathrm{~mL} \mathrm{~min}^{-1}$, UV at
$254 \mathrm{~nm}$ yielded $2(2.2 \mathrm{mg})$. The purification of fractions F33-36 (50 mg) was performed in a gradient mode as follow: 11 to $13 \%$ of $\mathrm{B}$ in $60 \mathrm{~min}$, injection of $500 \mu \mathrm{L}$ (10 $\mathrm{mg} \mathrm{mL}^{-1}$ ), flow rate $4.7 \mathrm{~mL} \mathrm{~min}^{-1}$, $\mathrm{UV}$ at $254 \mathrm{~nm}$ and yielded $3(1 \mathrm{mg})$ and 4 (1.2 mg).

\section{UPLC-TOF-HRMS analysis of the isolated compounds}

HRMS metabolite profiling of the extracts, fractions and pure products was performed on a Micromass-LCT Premier TOF mass spectrometer (Waters, Milford, MA, USA) equipped with an electrospray interface and coupled to an Acquity UPLC system (Waters, Milford, MA, USA) using a generic method previously described. ${ }^{23}$

UPLC-Orbitrap-HRMS analysis of the isolated compounds

Chromatographic separation was performed on a Waters Acquity UPLC system interfaced to a Q-Exactive Focus mass spectrometer (Thermo Scientific, Bremen, Germany), using a heated electrospray ionization (HESI-II) source. Thermo Scientific Xcalibur 3.1 software was used for instrument control. The LC conditions were as follows: column, Waters BEH C18 $(50 \times 2.1 \mathrm{~mm}$ i.d., $1.7 \mu \mathrm{m}$, Milford, MA, USA); mobile phase, (A) water with $0.1 \%$ formic acid, (B) acetonitrile with $0.1 \%$ formic acid; flow rate, $600 \mu \mathrm{L} \mathrm{min}{ }^{-1}$; injection volume, $2 \mu \mathrm{L}$; gradient, linear gradient of $5-100 \% \mathrm{~B}$ over $4 \mathrm{~min}$ and isocratic at $100 \%$ $\mathrm{B}$ for $1 \mathrm{~min}$. An Acquity UPLC PDA detector (Milford, MA, USA) was used to acquire UV spectra, which were collected from 210 to $450 \mathrm{~nm}$. In positive ion mode, diisooctyl phthalate $\mathrm{C}_{24} \mathrm{H}_{38} \mathrm{O}_{4}[\mathrm{M}+\mathrm{H}]^{+}$ion $(\mathrm{m} / \mathrm{z} 391.28429)$ was used as internal lock mass. The optimized HESI-II parameters were as follows: source voltage, $3.5 \mathrm{kV}$ (pos); sheath gas flow rate (N2), 55 units; auxiliary gas flow rate, 15 units; spare gas flow rate, 3.0; capillary temperature, $275.00{ }^{\circ} \mathrm{C}$ (pos), S-Lens RF Level, 45. The mass analyzer was calibrated using a mixture of caffeine, methioninearginine-phenylalanine-alanine-acetate (MRFA), sodium dodecyl sulfate, sodium taurocholate, and Ultramark 1621 in an acetonitrile/methanol/water solution containing $1 \%$ formic acid by direct injection. The data-dependent MS/MS events were performed on the three most intense ions detected in full scan MS (Top3 experiment). The MS/MS isolation window width was $1 \mathrm{Da}$, and the stepped normalized collision energy (NCE) was set to 15, 30 and 45 units. In data-dependent MS/MS experiments, full scans were acquired at a resolution of 35,000 full width at half maximum (FWHM) (at $m / z, 200$ ) and MS/MS scans at 17,500 FWHM both with an automatically determined maximum injection time. After being acquired in an 
MS/MS scan, parent ions were placed in a dynamic exclusion list for $2.0 \mathrm{~s}$.

Anisophenol (2)

Amorphous solid, UV (MeOH) $(\log \varepsilon) \lambda_{\max } / \mathrm{nm} 226.02$ (1.09), 296.2 (0.55); ${ }^{1} \mathrm{H}$ NMR (500 MHz, $\left.\mathrm{CD}_{3} \mathrm{OD}\right) \delta 1.47$ (s, 6H, $\mathrm{CH}_{3}-11,12$ ), 2.47 (d, 3H, J $0.9 \mathrm{~Hz}, \mathrm{CH}_{3}-13$ ), 5.74 (d, 1H, J 9.7 Hz, H-3), 6.39 (d, 1H, J 9.7 Hz, H-4), 6.53 (s, 1H, H-5), 6.74 (dd, 1H, J 8.7, $2.8 \mathrm{~Hz}, \mathrm{H}-4$ '), 6.88 (d, 1H, J 8.7 Hz, H-5'), 7.25 (d, 1H, J 2.8 Hz, H-2'), 7.36 (d, $1 \mathrm{H}, J 1.5 \mathrm{~Hz}, \mathrm{H}-8), 7.55$ (dt, $1 \mathrm{H}, J 1.5,0.9 \mathrm{~Hz}, \mathrm{H}-10$ ); ${ }^{13} \mathrm{C}$ NMR (126 MHz, CD $\left.\mathrm{OD}\right) \delta 22.0\left(\mathrm{CH}_{3}, \mathrm{C}-13\right), 27.6$ $\left(\mathrm{CH}_{3}, \mathrm{C}-11,12\right), 77.0$ (C, C-2), $104.9(\mathrm{CH}, \mathrm{C}-5), 108.8$ (CH, C-2'), 117.2 (CH, C-8), 117.7 (C, C-4a), 118.1 (CH, C-4'), 118.5 (CH, C-5'), 119.8 (CH, C-10), 120.9 (C, C-6a), 121.1 (C, C-1'), 123.4 (CH, C-4), 127.9 (C, C-7), 131.8 (CH, C-3), 137.6 (C, C-9), 141.7 (C, C-1a), 145.9 (C, C-6), 146.8 (C, C-6'), 154.1 (C, C-3'); ESI-TOF-MS: found $m / z 330.1251[\mathrm{M}]^{+}$(calcd. for $\mathrm{C}_{22} \mathrm{H}_{18} \mathrm{O}_{3}: 330.1256$; $\Delta \mathrm{ppm}=1.5)$.

\section{Yeast strains}

The Candida albicans DSY2621 and parent wild type CAF2-1 (ura3A::imm434/URA3) were obtained from Prof Dominique Sanglard (Institute of Microbiology, University of Lausanne and University Hospital Center). The C. albicans susceptible strain DSY2621 was constructed by targeted deletions of genes encoding membrane efflux

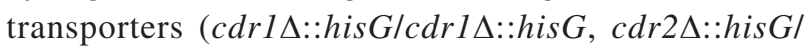

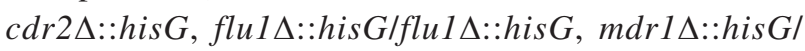
$m d r 1 \Delta:: h i s G)$ and calcineurin subunit $\mathrm{A}$ (cmpl $1 \Delta::$ hisG/ cmplA::hisG-URA3-hisG). ${ }^{24}$ The yeast strains were maintained on Sabouraud agar (peptone from meat, $5.0 \mathrm{~g} \mathrm{~L}^{-1}$; peptone from casein, $5.0 \mathrm{~g} \mathrm{~L}^{-1}$; D-(+)-glucose, $40.0 \mathrm{~g} \mathrm{~L} \mathrm{~L}^{-1}$; agar-agar, $15.0 \mathrm{~g} \mathrm{~L}^{-1}$; Merck, Darmstadt, Germany) Petri dishes.

\section{Biological assays}

The bioautography assay was an optimized version ${ }^{8}$ of a method published by Rahalison et al. ${ }^{25}$ Antifungal susceptibility testing was carried out on the basis of EUCAST protocols ${ }^{19,26}$ with slight modifications. Antifungal susceptibility assays on biofilms were conducted according to a published protocol. ${ }^{20}$

\section{Supplementary Information}

Supplementary information (1D and 2D NMR spectra of isolated compounds; dereplication peak list of DCM extract in positive and negative mode) is available free of charge at http://jbcs.sbq.org.br.

\section{Acknowledgments}

The authors are thankful to the Swiss National Science Foundation for providing financial support for this project, which aims to identify new antifungal compounds of natural origin (grant CR2313_143733 to J. L. W., E. F. Q., D. S. and K. G.). The authors would like to thank Prof Dr Maria S. de Stapf from Departamento de Botánica, Facultad de Ciencias Naturales, Exactas y Tecnología, Universidad de Panamá for the picture of Cordia anisophylla presented in the graphical abstract.

\section{References}

1. Miller, J. S.; Ann. Mo. Bot. Gard. 1989, 76, 593.

2. Ioset, J. R.; Marston, A.; Gupta, M. P.; Hostettmann, K.; Phytochemistry 1998, 47, 729.

3. Ioset, J. R.; Marston, A.; Gupta, M. P.; Hostettmann, K.; Phytochemistry 2000, 53, 613.

4. Ioset, J. R.; Marston, A.; Gupta, M. P.; Hostettmann, K.; J. Nat. Prod. 2000, 63, 424.

5. Nogueira, T. B. D. D.; Nogueira, R. B. D. D.; Silva, D. A. E.; Tavares, J. F.; Lima, E. D.; Pereira, F. D.; Fernandes, M. M. M. D.; de Medeiros, F. A.; Sarquis, R. D. F. R.; Braz Filho, R.; Maciel, J. K. D.; de Souza, M. D. V.; Molecules 2013, 18, 11086.

6. Favre-Godal, Q.; Dorsaz, S.; Queiroz, E. F.; Marcourt, L.; Ebrahimi, S. N.; Allard, P. M.; Voinesco, F.; Hamburger, M.; Gupta, M. P.; Gindro, K.; Sanglard, D.; Wolfender, J. L.; J. Nat. Prod. 2015, 78, 2994.

7. Favre-Godal, Q.; Dorsaz, S.; Marcourt, L.; Bertini, V.; Dormia, E.; Michellod, E.; Voinesco, F.; Gupta, M.; Gindro, K.; Sanglard, D.; Queiroz, E. F.; Wolfender, J. L.; J. Braz. Chem. Soc. 2017, $28,443$.

8. Favre-Godal, Q.; Dorsaz, S.; Queiroz, E. F.; Conan, C.; Marcourt, L.; Wardojo, B. P. E.; Voinesco, F.; Buchwalder, A.; Gindro, K.; Sanglard, D.; Wolfender, J. L.; Phytochemistry 2014, 105, 68.

9. Queiroz, M. M. F.; Queiroz, E. F.; Zeraik, M. L.; Marti, G.; Favre-Godal, Q.; Simoes-Pires, C.; Marcourt, L.; Carrupt, P. A.; Cuendet, M.; Paulo, M. Q.; Bolzani, V. S.; Wolfender, J. L.; Phytochem. Lett. 2014, 10, 1xxxviii.

10. Lim, C. S. Y.; Rosli, R.; Seow, H. F.; Chong, P. P.; Eur. J. Clin. Microbiol. Infect. Dis. 2012, 31, 21.

11. Guillarme, D.; Nguyen, D. T. T.; Rudaz, S.; Veuthey, J. L.; Eur. J. Pharm. Biopharm. 2007, 66, 475.

12. Guillarme, D.; Nguyen, D. T. T.; Rudaz, S.; Veuthey, J. L.; Eur. J. Pharm. Biopharm. 2008, 68, 430. 
13. Chien, Y. C.; Lin, C. H.; Chiang, M. Y.; Chang, H. S.; Liao, C. H.; Chen, I. S.; Peng, C. F.; Tsai, I. L.; Phytochemistry 2012 80,50 .

14. Modak, B.; Torres, R.; Lissi, E.; delle Monache, F.; Nat. Prod. Res. 2003, 17, 403.

15. Challal, S.; Queiroz, E. F.; Debrus, B.; Kloeti, W.; Guillarme, D.; Gupta, M. P.; Wolfender, J. L.; Planta Med. 2015, 81, 1636.

16. Howard, B. M.; Clarkson, K.; Bernstein, R. L.; Tetrahedron Lett. 1979, 20, 4449.

17. Schabauer, A.; Zutz, C.; Lung, B.; Wagner, M.; Rychli, K.; Front. Vet. Sci. 2018, 5, 148.

18. Chapman, H.; Dictionary of Natural Products on DVD; CRC Press, Taylor \& Francis Group: Boca Raton, Florida, USA, 2014. Available at http://dnp.chemnetbase.com, accessed in November 2018.

19. Tudela, J. L. R.; Donnelly, J. P.; Arendrup, M. C.; Arikan, S.; Barchiesi, F.; Bille, J.; Chryssanthou, E.; Cuenca-Estrella, M.; Dannaoui, E.; Denning, D.; Fegeler, W.; Gaustad, P.; Lass-Florl, C.; Moore, C.; Richardson, M.; Schmalreck, A.; Velegraki, J. A.; Verweij, P.; Clin. Microbiol. Infect. 2008, 14, 982.

20. Pierce, C. G.; Uppuluri, P.; Tristan, A. R.; Wormley Jr., F. L.; Mowat, E.; Ramage, G.; Lopez-Ribot, J. L.; Nat. Protoc. 2008 , 3,1494
21. Oza, M. J.; Kulkarni, Y. A.; J. Pharm. Pharmacol. 2017, 69, 755.

22. Birringer, M.; Siems, K.; Maxones, A.; Frank, J.; Lorkowski, S.; RSC Adv. 2018, 8, 4803.

23. Cabral, R. S.; Allard, P. M.; Marcourt, L.; Young, M. C.; Queiroz, E. F.; Wolfender, J. L.; J. Nat. Prod. 2016, 79, 2270.

24. Pascual, A.; Nieth, V.; Calandra, T.; Bille, J.; Bolay, S.; Decosterd, L. A.; Buclin, T.; Majcherczyk, P. A.; Sanglard, D.; Marchetti, O.; Antimicrob. Agents Chemother. 2007, 51, 137.

25. Rahalison, L.; Hamburger, M.; Hostettmann, K.; Monod, M.; Frenk, E.; Phytochem. Anal. 1991, 2, 199.

26. Rodriguez-Tudela, J. L.; Arendrup, M. C.; Barchiesi, F.; Bille, J.; Chryssanthou, E.; Cuenca-Estrella, M.; Dannaoui, E.; Denning, D. W.; Donnelly, J. P.; Dromer, F.; Fegeler, W.; Lass-Florl, C.; Moore, C.; Richardson, M.; Sandven, P.; Velegraki, A.; Verweij, P.; Clin. Microbiol. Infect. 2008, 14, 398.

Submitted: July 12, 2018

Published online: November 8, 2018 